
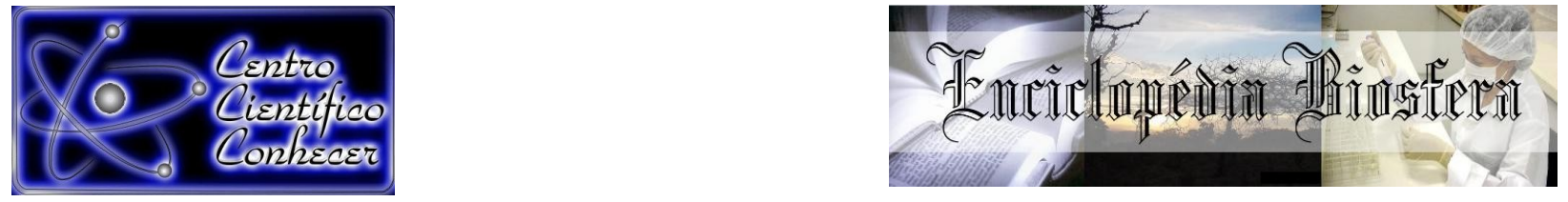

\title{
EFEITO DE FATORES ABIÓTICOS SOBRE A ATIVIDADE ENZIMÁTICA DE ACTINOBACTÉRIAS DE REGIÃO DO SEMIÁRIDO BRASILEIRO
}

Karoline Alves Ramos ${ }^{1}$; José Vinícius Leite Lima; Claudia Miranda Martins ${ }^{3}$; Suzana Claudia Silveira Martins ${ }^{4}$

1. Bacharela em Ciências Biológicas pela Universidade Federal do Ceará Campus do Pici, Fortaleza - Ceará, Brasil. E-mail: karolinea.ramos@gmail.com;

2. Docente no Curso de Biologia da Universidade Regional do Cariri, Campos Sales - Ceará, Brasil;

3. Docente do Departamento de Biologia da Universidade Federal do Ceará Campus do Pici, Fortaleza - Ceará, Brasil;

4. Docente do Departamento de Biologia da Universidade Federal do Ceará Campus do Pici, Fortaleza - Ceará, Brasil.

Recebido em: 06/04/2018 - Aprovado em: 10/06/2018 - Publicado em: 20/06/2018 DOI: 10.18677/EnciBio_2018A89

\begin{abstract}
RESUMO
As actinobactérias constituem um importante grupo microbiano e sua atividade enzimática contribui com a estruturação de comunidades do solo. Nesse contexto, avaliou-se o efeito de fatores abióticos no crescimento e atividade amilolítica de 18 cepas de actinobactérias reconhecidamente facilitadoras de rizóbios isoladas do Parque Nacional de Ubajara - Ceará, região do semiárido Nordestino Brasileiro. As cepas foram analisadas quanto as suas atividades amilolítica em diferentes faixas e concentrações de $\mathrm{pH}$ e salinidade. Constatou-se que as cepas apresentaram evidente atividade enzimática, exceto no $\mathrm{pH} 4$; e a análise de regressão linear forneceu um gráfico que demonstrou os maiores índices enzimáticos no $\mathrm{pH} 7$ e na concentração de $2 \%$ de $\mathrm{NaCl}$. Portanto, a atividade enzimática dessas cepas demonstrou o potencial dessas actinobactérias em manter os processos biológicos em que estão envolvidas mesmo em condições de estresse fisiológico, características dos solos de regiões semiáridas.
\end{abstract}

PALAVRAS-CHAVE: Alterações fisiológicas. Amilase. Solo

\section{EFFECT OF ABIOTIC FACTORS ON THE ENZYMATIC ACTIVITY OF ACTINOBACTERIA FROM THE BRAZILIAN SEMI-ARID REGION}

\begin{abstract}
Actinobacteria constitute an important microbial group and its enzymatic activity contributes to the structuring of soil communities. In this context, the present study tested the effect of abiotic factors on the growth and amylolytic activity of 18 strains of actinobacteria known to facilitate rhizobia isolated from the soil of the Parque Nacional de Ubajara - Ceará, a semiarid region of the Northeast of Brazil. The strains were evaluated for their amylolytic activity in different ranges and concentrations of $\mathrm{pH}$ and salinity. It was found that the strains showed enzymatic activity, except at $\mathrm{pH}$
\end{abstract}


4; linear regression analysis provided a plot showing the highest enzyme production indexes at $\mathrm{pH} 7$ and $2 \% \mathrm{NaCl}$ concentration. Therefore, the enzymatic activity of these actinobacteria have demonstrated their potential in maintaining the biological processes even under conditions of physiological stress, which are typical characteristics of the soils of semiarid regions.

KEYWORDS: Physiological alterations. Amylase. Soil.

\section{INTRODUÇÃO}

A região semiárida se caracteriza por solos com baixa disponibilidade de nutrientes e elevadas concentrações salinas (ZANELLA, 2014; FREITAS et al., 2007). A diversidade de vegetações, clima quente e seco, amplitudes térmicas elevadas e pouca umidade do solo também predominam nessa região (KAVAMURA et al., 2013). Essas características configuram um ambiente estressante para os organismos em geral e, em particular, para os microrganismos. No entanto, a literatura destaca que as actinobactérias constituem um grupo microbiano abundante e diverso no solo destas regiões (PINHEIRO et al., 2014; BRITO et al., 2015; SILVA et al., 2015).

A diversidade metabólica das actinobactérias é um dos fatores que possibilita o crescimento e sobrevivência desse grupo nos mais diferentes e estressantes ambientes, como regiões do semiárido (SUNEETHA et al., 2011; MANSOUR et al., 2015). Os produtos do metabolismo secundário dessas bactérias desempenham papel relevante para a manutenção vegetal e microbiana do solo (GONZÁLEZ et al., 2005). Alguns autores, como Bais et al. (2010), destacam a importância das actinobactérias na rizosfera, região do solo influenciada pelas raízes que produzem diferentes exsudatos que favorecem a atividade e diversidade microbiana nessa área (DANTAS et al., 2011).

Entre os metabólitos secundários produzidos pelas actinobactérias estão as enzimas extracelulares, que hidrolisam macromoléculas complexas, disponibilizando energia e nutrientes necessários, para entre outras funções, as interações metabólicas entre organismos do solo (EL-TARABILY et al., 2009; PALANIYANDI, 2014; PANDE et al., 2014). Essa atividade enzimática é influenciada por diversos fatores, tais como $\mathrm{pH}$, temperatura, salinidade, sendo todos estes parâmetros fisiológicos muito variáveis em solos rizosférico, principalmente da região do semiárido (GUPTA et al., 2003; SOUZA et al., 2010).

Tendo em conta que um dos substratos mais abundantes no solo é o amido, polissacarídeo complexo, degradado pelas amilases (VAN DER MAAREL et al., 2002; GUPTA et al., 2003), estudos sobre a influência de fatores abióticos na atividade amilolítica de actinobactérias do semiárido podem contribuir para compreensão desse ecossistema tão importante. Dessa forma, objetivou-se com este trabalho avaliar o efeito de fatores abióticos na atividade enzimática de actinobactérias facilitadoras do crescimento de rizóbios oriundas de solo rizosférico de região semiárida.

\section{Área de estudo}

\section{MATERIAL E MÉTODOS}

Foram avaliadas actinobactérias isoladas a partir de amostras de solo rizosférico do Parque Nacional de Ubajara (PNU), classificada como unidade de conservação que se localiza no Planalto da Ibiapaba, ao norte do Estado do Ceará a $320 \mathrm{~km}$ de Fortaleza, limitando-se com o Estado do Piauí. O PNU está compreendido entre a latitude $3^{\circ} 46^{\prime} \mathrm{S}$ e longitude $40^{\circ} 54^{\prime} \mathrm{W}$ com altitudes que variam 
de 800 a 1.100 m (CUNHA; ARAÚJO, 2014). A temperatura média é de 20 a $22^{\circ} \mathrm{C}$ no planalto da Ibiapaba e em torno de 24 a $26^{\circ} \mathrm{C}$ na depressão periférica, tendo sua média pluviométrica em torno de $1.463 \mathrm{~mm}$ por ano (IBAMA, 2006).

\section{Actinobactérias}

A partir das amostras de solo rizosférico foram isoladas 28 cepas de actinobactérias caracterizadas culturalmente por Ramos et al. (2015) e micromorfologicamente por Brito et al. (2015). Essas cepas foram denominadas com código (UB-número da cepa). A atividade amilolítica dessas cepas foi previamente avaliada, o Índice Enzimático (IE) estabelecido e aquelas com IE $\geq 2,0$ foram testadas quanto atividade sinergística com cepas de rizóbios isoladas da mesma área, mas deficientes na produção de amilase (SILVA, 2016). As cepas de actinobactérias UB-02, UB-03, UB-04, UB-05, UB-07, UB-08, UB-11, UB-14, UB-15, UB-17, UB-18, UB-19, UB-20, UB-21, UB-23, UB-24, UB-26 e UB-27 metabolicamente compatíveis com as de rizóbios foram selecionadas para 0 presente estudo. Essas cepas são mantidas em tubos inclinados com meio caseína dextrose ágar (CDA) (CLARK, 1965) a $4^{\circ} \mathrm{C}$ no Laboratório de Microbiologia Ambiental (LAMAB) do Departamento de Biologia da Universidade Federal do Ceará, compondo coleção de actinobactérias oriundas do semiárido do Nordeste brasileiro.

\section{Efeito do pH e salinidade sobre a atividade enzimática das cepas de actinobactérias metabolicamente compatíveis com rizóbios}

O efeito dos fatores abióticos $\mathrm{pH}(4,5,7$ e 9) e salinidade $(1,0,2,0,3,0$ e 4,0\% de $\mathrm{NaCl}$ ) sobre a atividade amilolítica das cepas de actinobactérias metabolicamente compatíveis com cepas de rizóbios foi avaliado segundo a metodologia de Alariya et al. (2013). Nesta técnica, as cepas de actinobactérias selecionadas foram inoculadas na forma de spots e em triplicata no meio de cultura ágar-amido, com a seguinte composição por litro: peptona $(10,0 \mathrm{~g})$, extrato de carne $(3,0 \mathrm{~g}), \mathrm{NaCl}(5,0$ $\mathrm{g})$, amido solúvel $(2,0 \mathrm{~g})$ e ágar $(15,0 \mathrm{~g})$.

\section{$\mathrm{pH}$}

Para testar o efeito do $\mathrm{pH}$ as cepas foram incubadas em câmara de crescimento B.O.D. a $28 \pm 2^{\circ} \mathrm{C}$ por 10 dias, em meio de cultura ágar-amido que teve seu pH ajustado para 4, 5, 7 e 9 (ALARIYA et al., 2013, modificado).

\section{Concentrações salinas}

Para o referido teste o meio ágar-amido teve sua concentração de $\mathrm{NaCl}$ ajustada para $1,0,2,0,3,0$ e $4,0 \%$. As cepas foram inoculadas em cada concentração anteriormente citadas e incubadas em câmara B.O.D. a $28 \pm 2^{\circ} \mathrm{C}$ por 10 dias, mantendo o pH 6,5-7,1 (ALARIYA et al., 2013, modificado).

\section{Índice Enzimático}

Após o período de incubação foram adicionados $10 \mathrm{~mL}$ de solução lugol em cada placa de modo a evidenciar o halo de degradação enzimática (ALARIYA et al., 2013). A atividade amilolítica em todos os pHs e salinidades testados foi expressa como índice enzimático (IE), que foi determinado utilizando-se a seguinte equação: $\mathrm{IE}=\mathrm{Dh} / \mathrm{Dc}$. Sendo Dh o diâmetro médio em mm do halo de hidrólise e Dc o diâmetro médio em mm da colônia das actinobactérias (HANKIN; ANAGNOSTAKIS, 1975). 
Os ensaios, realizados em triplicata, sendo cada repetição constituída por uma placa de Petri, obtiveram um IE médio, além do desvio padrão. Os dados de índice enzimático foram submetidos a uma análise de regressão linear no software gratuito RStudio ${ }^{\circledR}$ (R DEVELOPMENT CORE TEAM, 2011), com 5\% de significância. Essa análise foi utilizada para modelar a relação entre as variáveis quantitativas.

\section{RESULTADOS E DISCUSSÃO}

Efeito do pH e salinidade sobre a atividade enzimática das cepas de actinobactérias metabolicamente compatíveis com rizóbios

As cepas de actinobactérias apresentaram evidente desempenho na hidrólise de amido, mesmo sob as condições extremas de $\mathrm{pH}$ e salinidade avaliadas, como exemplificado na Figura 1, na qual a cepa UB-11 apresentou o halo de degradação do amido bem evidente nas placas do teste de salinidade para a concentração de $1 \%$ de $\mathrm{NaCl}$.

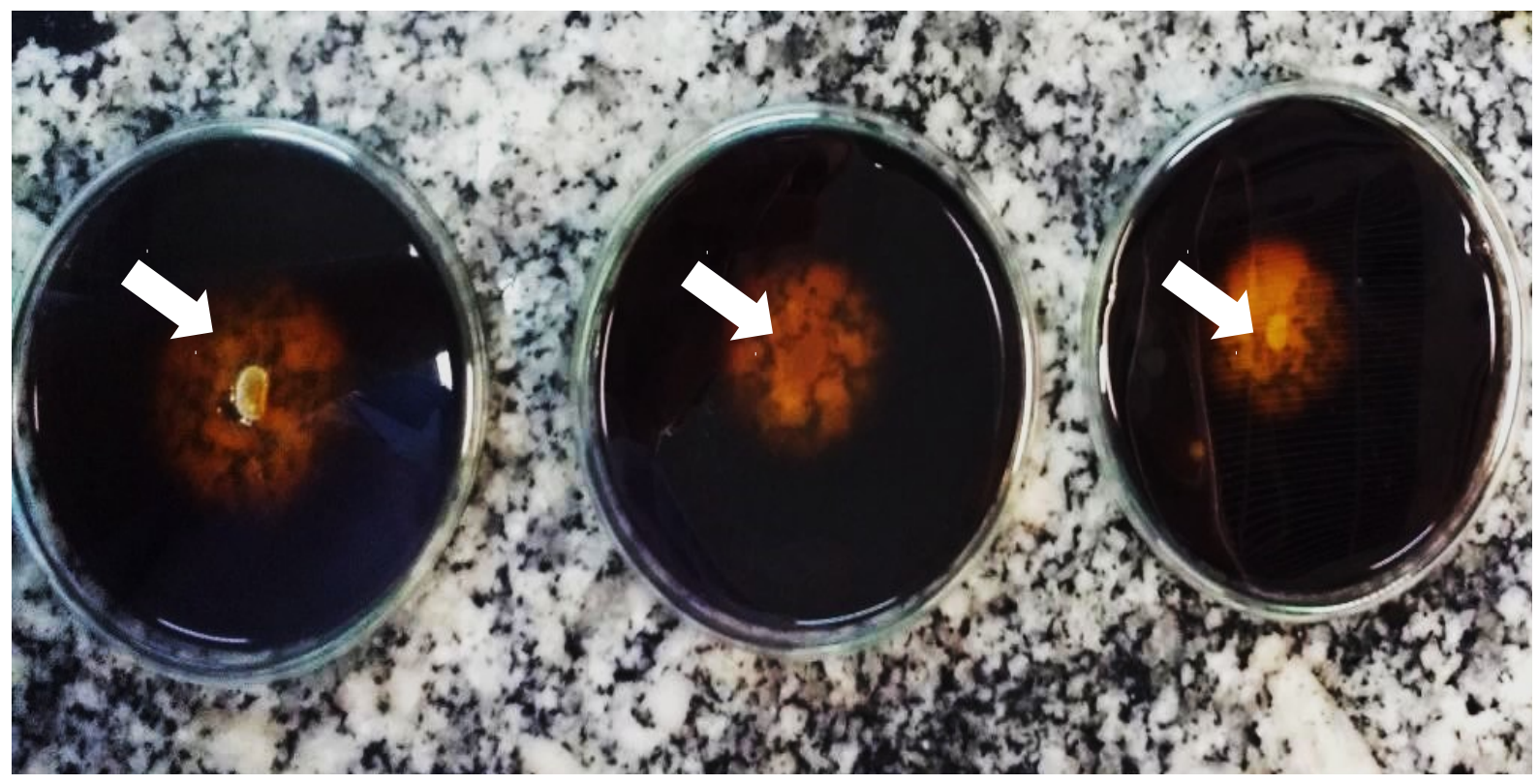

FIGURA 1: Atividade amilolítica da cepa UB-11 no teste com $\mathrm{NaCl} 1 \%$. As setas nas zonas claras ao redor da colônia indicam o halo de degradação, relativo à atividade amilolítica da actinobactéria.

pH

Das 18 cepas de actinobactérias testadas quanto a capacidade de degradação dos compostos amilolíticos nos diferentes pHs, nenhuma cepa de actinobactéria se desenvolveu no meio suplementado com amido no pH 4, dessa forma não foi possível calcular o índice enzimático (IE).

Já no $\mathrm{pH} 5,6$ cepas $(33,33 \%)$ foram capazes de crescer e apresentar amilase positiva, com valores do índice enzimático na faixa de $1,5>I E<5$. Nesse $\mathrm{pH}$ foi possível registrar que a cepa UB-20 apresentou o maior halo de hidrólise $(30,68$ $\mathrm{mm}$ ) (Figura 2). 


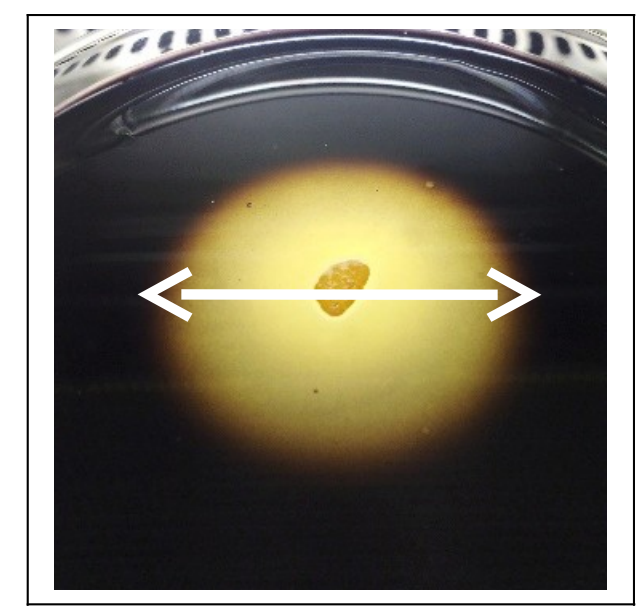

FIGURA 2: Halo de hidrólise pela amilase da cepa UB-20 no pH 5. A seta dupla indica o diâmetro do halo.

Nos pHs 7 e 9 todas as cepas apresentaram amilase positiva, destacando-se as cepas UB-23, com um índice enzimático maior que $6 \mathrm{no} \mathrm{pH} \mathrm{7,} \mathrm{e} \mathrm{as} \mathrm{cepas} \mathrm{UB-05}$ e UB-08, com valor maior que 4, mesmo com o aumento do $\mathrm{pH}$. Além disso, é possível observar que o índice enzimático nos diferentes $\mathrm{pH}$ variou de 1,5 a 6,7, sendo o menor IE registrado no pH 9 e o maior IE no pH 7 (Figura 3), podendo esse maior IE ser atribuído ao $\mathrm{pH}$ ótimo de crescimento das actinobactérias ser na faixa de neutralidade (BARKA et al., 2016).

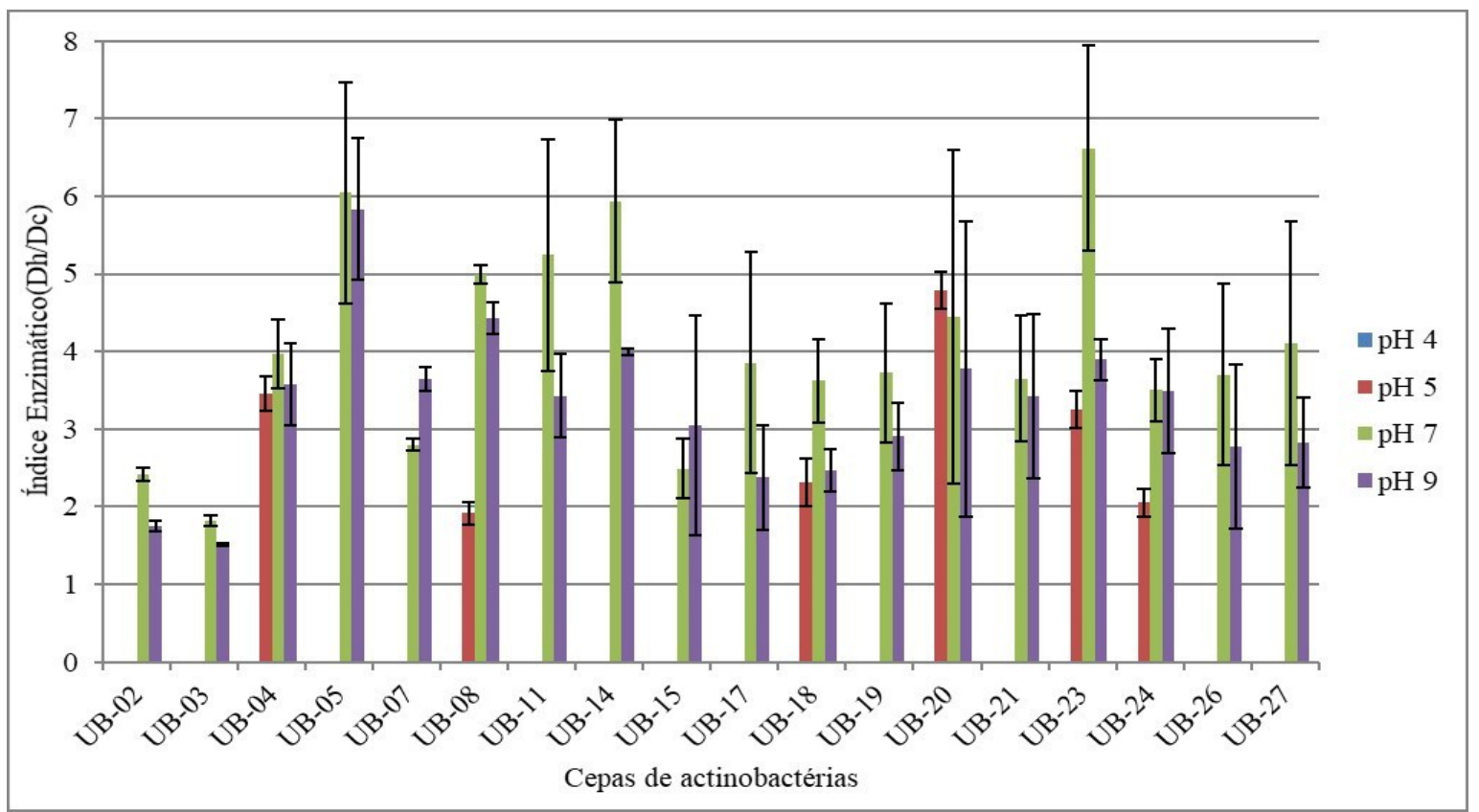

FIGURA 3: Perfil da atividade amilolítica das cepas de actinobactérias em diferentes pHs.

Conforme Ramos et al. (2015) e Brito et al. (2015) em experimentos sobre as características culturais e micromorfológicas, Streptomyces representa $55,56 \%$ dos 
gêneros das cepas de actinobactérias deste estudo. Dessa forma, além do seu conhecido potencial enzimático, os resultados do presente trabalho demonstram que esse gênero tolera uma ampla faixa de $\mathrm{pH}$ sem perder a capacidade de crescer, principalmente com uma suplementação do meio (KONTRO et al., 2005), isso explica o fato de que mesmo com valores tão extremos de $\mathrm{pH}$ ainda foi possível observar crescimento e atividade enzimática, pois o meio contém peptona, além do amido.

No seu estudo sobre actinobactérias na Estação Ecológica de Aiuaba - CE, Lima et al. (2017) constataram que as cepas dos dois gêneros de actinobactérias testados (Streptomyces e Saccharothrix) tiveram comportamentos diferentes em todos os pHs, porém nos pH 7,0 e 8,0 todas apresentaram crescimento. Ressalte-se que embora as cepas estudadas também sejam oriundas de uma região do semiárido (Aiuaba) é possível que o solo apresente características diferentes em relação ao solo do PNU. Importante destacar que nesse estudo os autores registraram que $71 \%$ das cepas cresceram em todos os $\mathrm{pHs}$.

Pode-se observar que, apesar das actinobactérias serem capazes de colonizar ambientes extremos, como por exemplo, caracterizados por pHs ácidos ou alcalinos (ZENOVA et al., 2011), a atividade amilolítica não foi constatada no pH mais ácido testado, no entanto apresentaram crescimento acentuado nos demais pHs.

Sanomiya e Nahas (2003), estudando a influência do pH nas atividades enzimáticas dos microrganismos, constataram que o $\mathrm{pH}$ do solo afetava a frequência de bactérias amilolíticas, enquanto Maccheroni Jr. et al. (2004), verificaram que em meio solidificado, a produção de amilase por isolados de Colletotrichum obedecia a um padrão dependente do $\mathrm{pH}$ ambiental.

Outros trabalhos revelam o potencial desse grupo microbiano em se desenvolver em regiões com solos muito ácidos (ZENOVA et al., 2011) e bastante alcalinos (SHIVLATA; SATYANARAYANA, 2015). Dessa forma, os resultados do presente estudo, demonstram que as actinobactérias apresentaram um perfil fisiológico compatível com ambientes em condições de estresse.

\section{Concentrações salinas}

Em relação à atividade amilolítica em diferentes concentrações de $\mathrm{NaCl}$, as 18 cepas de actinobactérias cresceram em todas as concentrações testadas. Um fato interessante a se destacar é que as cepas UB-02 e UB-03 cresceram, mas não apresentaram halo de hidrólise nas concentrações $\mathrm{NaCl} 2 \%, 3 \%$ e $4 \%$, por esse motivo não foi possível calcular o IE (Figura 4). O crescimento dessas cepas pode ser atribuído à presença de peptona como fonte de carbono e energia na composição do meio de cultura, ou mesmo que essas cepas hidrolisaram parcialmente $o$ amido. 


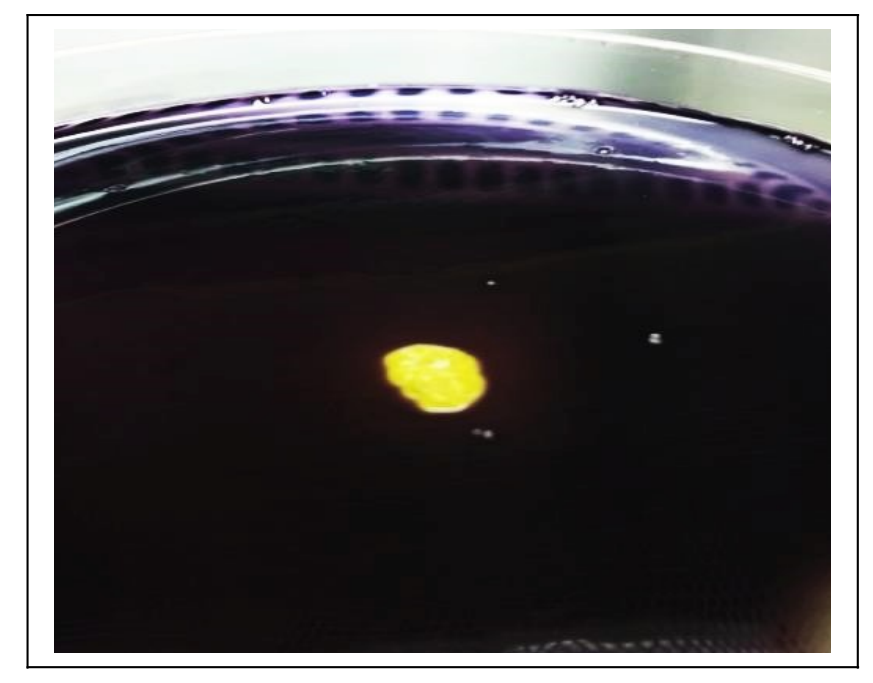

FIGURA 4: Crescimento da cepa UB-02 na concentração de $\mathrm{NaCl} 2 \%$ demonstrando a ausência do halo de degradação do amido.

$\mathrm{Na}$ concentração de $1 \%$ de $\mathrm{NaCl}$, todas as cepas foram capazes de crescer e apresentar amilase positiva, evidenciado pelo halo de degradação. $O$ índice enzimático variou de 1,9 para a cepa UB-02 a 5,7 para a cepa UB-05 (Figura 5). Além disso, é importante enfatizar que a cepa UB-20, assim como no pH 5, apresentou o maior halo nessa concentração de $\mathrm{NaCl}$ e a cepa UB-02, apesar do menor tamanho de colônia, apresentou halo, demonstrando a sua capacidade de degradação dos compostos amilolíticos do meio nessa concentração. Esse resultado reforça a importância do índice enzimático, onde se considera não somente o diâmetro do halo de hidrólise, mas também o tamanho da colônia.

Um percentual de $88,89 \%$ das cepas de actinobactérias apresentaram atividade amilolítica na concentração de $2 \%$ de $\mathrm{NaCl}$. Os IE das 16 cepas foram superiores a 2,5 , tendo a cepa UB-08 o maior IE $(6,1)$ e a UB-15 o menor IE $(2,1)$ (Figura 5). Tanto na concentração de $3 \%$ de $\mathrm{NaCl}$ quanto na concentração de $4 \%$, as maiores concentrações de $\mathrm{NaCl}$ testadas, todas as cepas apresentaram crescimento, porém apenas 16 cepas $(88,89 \%)$ produziram halo de hidrólise. Em $3 \%$ de $\mathrm{NaCl}$, apenas a cepa UB-15 apresentou um índice enzimático menor que 2, porém na concentração de $4 \%$ de $\mathrm{NaCl}$ essa cepa já demonstrou um IE superior. O contrário aconteceu para a cepa UB-23, que mostrou um IE de 2,3 na concentração de $2 \% \mathrm{NaCl}$ e na concentração de $4 \%$ referido parâmetro foi 1,79 (Figura 5). 


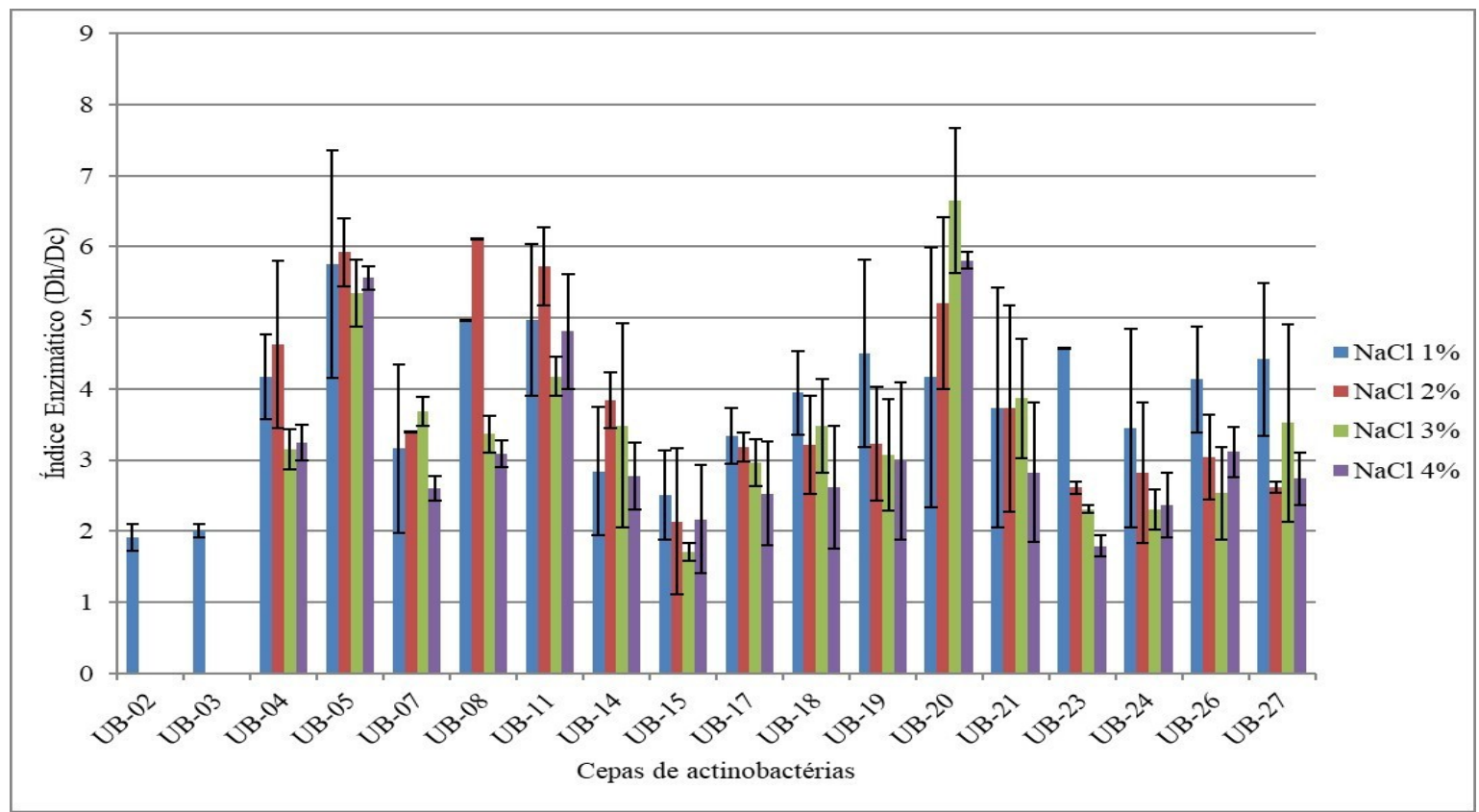

FIGURA 5: Perfil da atividade amilolítica das cepas de actinobactérias em diferentes concentrações de $\mathrm{NaCl}$.

$\mathrm{Na}$ literatura não foram encontradas referências a estudos sobre a atividade enzimática de actinobactérias em função da salinidade, porém Coronado et al. (2000) constataram a maior produção de amilase de uma cultura de Halomonas meridiana em meio de crescimento com amido numa concentração de $5 \%$ de $\mathrm{NaCl}$. Embora a concentração de $\mathrm{NaCl}$ testada neste trabalho tenha sido até $4 \%$, foi possível observar que todas as cepas de actinobactérias foram produtoras de amilase, pois, mesmo com as condições impostas, até $88,89 \%$ apresentaram atividade enzimática em todas as concentrações de $\mathrm{NaCl}$ testadas. Diante disso, pode-se inferir que essas cepas são tolerantes e aclimatam-se rapidamente aos níveis de salinidade acumulando osmólitos nas células (HAGEMANN, 2010) para assim neutralizarem o baixo potencial osmótico no meio e conseguirem crescer.

Oliveira et al. (2010) relacionaram o comportamento enzimático de rizóbios às condições fisiológicas dos solos da Amazônia, habitat do qual foram isolados. Assim, é possível que a atividade enzimática das cepas de actinobactérias registradas nas condições salinas mais extremas seja referente a um processo adaptativo dessas cepas aos solos salinos da região semiárida.

Em trabalho realizado com actinobactérias de material de compostagem, Akond et al. (2016) consideraram esses microrganismos como capazes de resistir a salinidade, ou seja, a uma tensão halotolerante, pois constataram que até nas concentrações de $8 \%$ de $\mathrm{NaCl}$ foi observado crescimento acentuado. Dessa forma, podemos considerar que, no presente estudo, as actinobactérias testadas apresentam certo nível de halotolerância, pois mais de $80 \%$ das cepas de actinobactérias ainda apresentou atividade amilolítica na maior concentração testada.

Segundo Goel et al. (2012), as restrições ambientais têm como consequência a limitação da distribuição de microrganismos, porém ao demonstrando esse amplo perfil fisiológico, as actinobactérias supostamente passaram por um processo adaptativo, aumentando assim sua capacidade de sobreviver e se manter nesse ambiente extremo. Inclusive, tendo que os solos semiáridos são caracteristicamente salinos (OSHONE et al., 2013), o comportamento dessas actinobactérias 
demonstrou a facilidade que esses microrganismos possuem nos mais diversos ambientes (SHIVLATA; SATYANARAYANA, 2015) e a possível importância desse grupo na constituição microbiana dos solos da região do PNU.

Os resultados obtidos com estas análises também são importantes do ponto de vista das interações ecológicas. Sousa et al. (2008) afirmaram que a salinidade do solo e os níveis de $\mathrm{pH}$ são fatores abióticos que podem interferir com a capacidade competitiva dos microrganismos. Assim, a tolerância para alta salinidade e baixo valores de $\mathrm{pH}$ são critérios para a seleção de microrganismos visando adaptação em solos salinos ou ácidos de forma que os mesmos sejam capazes de realizar suas funções biológicas no ecossistema. Como as cepas de actinobactérias utilizadas foram selecionadas por apresentarem $I E \geq 2,0$ (amilolítico) e interagirem positivamente com cepas de rizóbios (SILVA, 2016), é importante destacar que mesmo nas condições extremas a que foram submetidas in vitro, essas actinobactérias continuaram a ter atividade enzimática. Essa característica adaptativa pode contribuir para a permanência e sobrevivência de outros grupos microbianos por mecanismos de cooperação metabólica entre actinobactérias e rizóbios.

No referido trabalho, a interação metabólica para o amido foi testada em condições ambientais ótimas para os dois grupos de bactérias. Dessa forma, os resultados do presente estudo sugerem que interação continuaria ocorrendo mesmo em condiçoes extremas, e, assim, as actinobactérias poderiam aumentar o fitness das bactérias fixadoras de nitrogênio (GOEL et al., 2012) em solos de regiões semiáridas, garantindo a coexistência entre os dois grupos.

\section{Análises estatísticas}

A análise de regressão linear mostrou que os fatores abióticos $\mathrm{pH}$ e salinidade tiveram efeito significativo no índice enzimático das cepas de actinobactérias. Para o $\mathrm{pH}, \mathrm{R}^{2}=0,6916, \mathrm{p}<0,05$.

Dessa forma, como esperado, os maiores índices enzimáticos foram registrados no $\mathrm{pH} 7$ (Figura 6), próximo a faixa de $\mathrm{pH}$ ótimo para o crescimento dessas actinobactérias. Embora se tratando de outro grupo bacteriano, Oliveira et al. (2006) concluíram que, embora a atividade amilolítica de cepas de rizóbios tenha variado em função do $\mathrm{pH}$ do meio, os maiores índices foram registrados em pH 6,5.

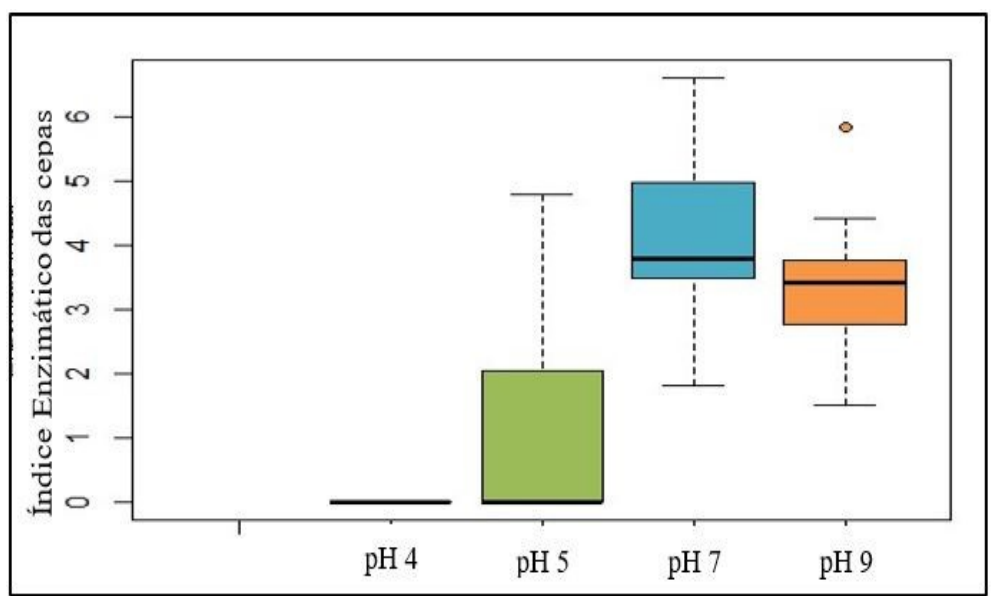

FIGURA 6: Distribuição de índices enzimáticos das cepas de actinobactérias em relação a diferentes pHs. 
O teste com $\mathrm{NaCl}$ entre as cepas de actinobactérias não apresentou diferença significativa $(p=0.2395)$, com $R^{2}=0,05963$. Esse fato pode ser explicado devido aos outliers, que representam os índices enzimáticos das cepas UB-05, UB-11 e UB-20, estarem acima do limite superior do bloxpot e as cepas UB-15 e UB-23, abaixo do limite inferior.

Embora os índices enzimáticos tenham variado de forma não significativa em relação à concentração salina, como supracitado, os maiores índices foram agrupados na concentração de 1 e $2 \%$ de $\mathrm{NaCl}$ (Figura 7 ).

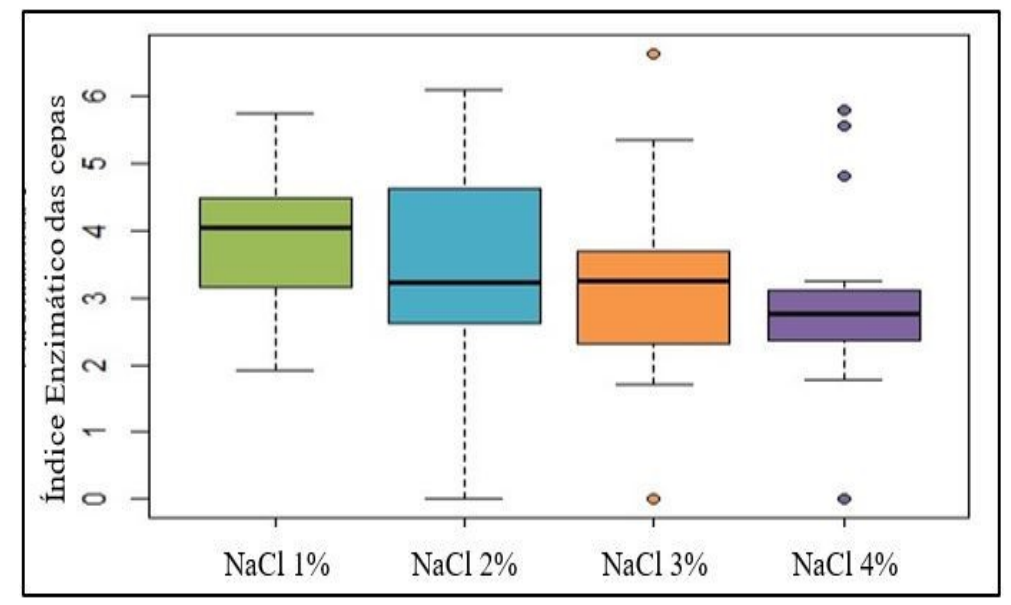

FIGURA 7: Distribuição de índices enzimáticos das cepas de actinobactérias em relação a diferentes concentrações salinas.

Como especificado por Sudharhsan et al. (2007), os resultados deste trabalho confirmaram a importância dos fatores abióticos na síntese e secreção de amilases microbianas. Assim, a atividade amilolítica configura um indicativo da presença de enzimas hidrolíticas no solo do PNU.

Importante ressaltar que o comportamento enzimático das cepas de actinobactérias é função do ambiente de onde foram isoladas. A esse respeito, Gorlach-Lira e Coutinho (2007) discutem que a reduzida disponibilidade de nutrientes e condições abióticas extremas, prevalentes no semiárido, influencia a atividade bioquímica do solo rizosférico, particularmente a produção de enzimas hidrolíticas, afetando o crescimento, sobrevivência e estruturação das populações microbianas desse ambiente.

\section{CONCLUSÃO}

As actinobactérias do Parque Nacional de Ubajara, no semiárido Nordestino, apresentaram atividade amilolítica em condições de $\mathrm{pH}$ e salinidade extremas, o que implica na disponibilização de nutrientes e energia necessários para manutenção de processos químicos e biológicos desse ecossistema.

\section{REFERÊNCIAS}

AKOND, M. A.; JAHAN, M. N.; SULTANA, N.; RAHMAN, F. Effect of temperature, pH and $\mathrm{NaCl}$ on the isolates of actinomycetes from straw and compost samples from Savar, Dhaka, Bangladesh. American Journal of Microbiology and Immunology, v.1, n.2, p.10-15, 2016. Disponível em: <http://files.aiscience.org/journal/article/html/70500008.html>. 
ALARIYA, S. S.; SETHI, S.; GUPTA, S.; LAL, G. B. Amylase activity of a starch degrading bacteria isolated from soil. Archives of Applied Science Research, v. 5, n. $1, \quad$ p. $15-24, \quad 2013 . \quad$ Disponível em: <http://www.scholarsresearchlibrary.com/archive/aasr-volume-5-issue-1-year2013.html>.

BAIS, H. P.; WEIR, T. L.; PERRY, L. G.; GILROY, S.; VIVANCO, J. M. The role of root exudates in rhizosphere interactions with plants and other organisms. Annual Review of Plant Biology, v.57, p.233-266, 2010. Disponível em: <https://www.annualreviews.org/doi/10.1146/annurev.arplant.57.032905.105159 >.

BARKA, E. A.; VATSA, P.; SANCHEZ, L.; GAVEAU-VAILLANT, N.; JACQUARD, C. et al. Taxonomy, physiology, and natural products of Actinobacteria. Microbiology and Molecular Biology Reviews, v.80, n.1, p.1-43, 2016. Disponível em: <http://mmbr.asm.org/content/80/1/1.short>. DOI: 10.1128/mmbr.00019-15.

BRITO, F. A. E.; RAMOS, K. A.; DA SILVA, R. M.; MARTINS, C. M.; MARTINS, S. C. S. Actinobacteria from rizospheric soil in the caatinga biome. Enciclopédia Biosfera, v.11, p.1992-2004, 2015.

CLARK, F.E. Actinomyces. In: BLACK, C.A. (Org.). Methods of soil analysis. Madison. American Society of Agronomy. 1965. p. 1498-501.

CORONADO, M. J.; VARGAS, C.; HOFEMEISTER, J.; VENTOSA, A.; NIETO, J. J. Production and biochemical characterization of an a-amylase from the moderate halophile Halomonas meridiana. FEMS Microbiology Letters, v. 183, n. 1, p. 67-71, 2000. Disponível: <https://academic.oup.com/femsle/article/183/1/67/552769>. DOI: 10.1111/j.1574-6968.2000.tb08935.x.

CUNHA, B. B.; ARAÚJO, R. C. P. Avaliação das pressões e ameaças ambientais sobre o Parque Nacional de Ubajara-Ceará: Uma perspectiva da Efetividade de Gestão. REDE - Revista Eletrônica do Prodema, v. 8, n. 1, 2014.

DANTAS, J. S.; SOUZA, A. P. D.; FARIAS, M. F. D.; NOGUEIRA, V. D. F. B. Interações entre grupos de microrganismos com a rizosfera. Revista Brasileira de Tecnologia Aplicada nas Ciências Agrárias, v. 2, n. 2, p. 213-224, 2011.

EL-TARABILY, K. A.; NASSAR, A. H.; HARDY, G. S. J.; SIVASITHAMPARAM, K.

Plant growth promotion and biological control of Pythium aphanidermatum, a pathogen of cucumber, by endophytic actinomycetes. Journal of Applied Microbiology, v. 106, n. 1, p. 13-26, 2009. Disponível em: <https://onlinelibrary.wiley.com/doi/full/10.1111/j.1365-2672.2008.03926.x>. DOI: 10.1111/j.1365-2672.2008.03926.x.

FREITAS, A. D. S. de; VIEIRA, C. L.; SANTOS, C. E. R. S.; Stamford, N. P.; LYRA, M. C. C. P. de. Caracterização de rizóbios isolados de Jacatupé cultivado em solo 
salino do estado de Pernambuco, Brasil. Bragantia, v. 66, n. 3, p. 497-504, 2007. Disponível em: <http://www.redalyc.org/articulo.oa?id=90866317>.

GOEL, A.; WORTEL, M. T.; MOLENAAR, D.; TEUSINK, B. Metabolic shifts: a fitness perspective for microbial cell factories. Biotechnology Letters, v. 34, n. 12, p. 21472160, 2012. Disponível em: <https://link.springer.com/article/10.1007/s10529-0121038-9\#citeas>. DOI: 10.1007/s10529-012-1038-9.

GONZÁlEZ, I.; AYUSO-SACIDO, A.; ANDERSON, A.; GENILLOUD, O. Actinomycetes isolated from lichens: Evaluation of their diversity and detection of biosynthetic gene sequences. FEMS Microbiology Ecology, v.54, p.401-415, 2005. Disponível em: <https://academic.oup.com/femsec/article/54/3/401/679600>. DOI: 10.1016/j.femsec.2005.05.004.

GORLACH-LIRA, K.; COUTINHO, H. D.M., 2007. Population dynamics and extracellular enzymes activity of mesophilic and thermophilic bacteria isolated from semi-arid soil of northeastern brazil. Brazilian Journal of Microbiology, v. 38, n.1, p. 135-141, 2007. Disponível em: <http://dx.doi.org/10.1590/S151783822007000100028>. DOI: 10.1590/s1517-83822007000100028.

GUPTA, R; MOHAPATRA, H; GOSWAMI, V.K.; CHAUHAN, B. Microbial $\alpha-$ Amylases: a biotechnological perspective. Process Biochemistry, v. 38, n. 11, p. 118, 2003. Disponível em: <https://www.sciencedirect.com/science/article/pii/S0032959203000530>. DOI: 10.1016/s0032-9592(03)00053-0.

HAGEMANN, M. Molecular biology of cyanobacterial salt acclimation. FEMS Microbiology Reviews, v. 35, n. 1, p. 87-123, 2010. Disponível em: < https://academic.oup.com/femsre/article/35/1/87/515013>. DOI: 10.1111/j.15746976.2010.00234.x.

HANKIN, L., ANAGNOSTAKIS, S. L. Solid media containing carboxy methylcellulose to detect cellulase activity of microorganisms. Journal of General Microbiology, v.98, n.1, p. 109-115, 1977. Disponível em: <http://dx.doi.org/10.1099/00221287-981-109>. DOI: 10.1099/00221287-98-1-109.

IBAMA - INSTITUTO BRASILEIRO DO MEIO AMBIENTE E RECURSOS NATURAIS RENOVÁVEIS. 2006. Plano operativo de prevenção e combate aos incêndios florestais do Parque Nacional de Ubajara. Ubajara. Disponível em: $<$ http://www.ibama.gov.br/phocadownload/prevfogo/planos_operativos/12parque_nacional_de_ubajara-ce.pdf>. Acesso em 08 jun 2017.

KAVAMURA, V. N.; TAKETANI, R. G.; LANÇONI, M. D.; ANDREOTE, F. D.; MENDES, R.; MELO, I. S. de. Water regime influences bulk soil and rhizosphere of Cereus jamacaru bacterial communities in the Brazilian Caatinga biome. PloS one, v. 8, n. 9, p. e73606, 2013. Disponível em: <http://journals.plos.org/plosone/article? $\mathrm{id}=10.1371$ journal.pone.0073606>. DOI: 10.1371/journal.pone.0073606.

KONTRO, M.; LIGNELL, U.; HIRVONEN, M. R.; NEVALAINEN, A. pH effects on 10 Streptomyces spp. growth and sporulation depend on nutrients. Letters in Applied 
Microbiology, v. 41, n. 1, p. 32-38, 2005. Disponível em: <https://onlinelibrary.wiley.com/doi/full/10.1111/j.1472-765X.2005.01727.x>. DOI: 10.1111/j.1472-765x.2005.01727.x.

LIMA, J. V. L.; MARTINS, S. C. S.; DE SIQUEIRA, K. A.; SOARES, M. A.; MARTINS, C. M. Characterization of actinobacteria from the semiarid region, and their antagonistic effect on strains of rhizobia. African Journal of Biotechnology, v. 16, n. 11, p. 499-507, 2017. DOI: 10.5897/ajb2016.15724.

MACCHERONI JR, W.; ARAÚJO, W. L.; AZEVEDO, J. L. Ambient pH-regulated enzime secretion in endophytic and pathogenic isolates of the fungal genus Colletotrichum. Scientia Agricola, v. 61, n. 3, p. 298-302, 2004. Disponível em: $<$ http://www.scielo.br/scielo.php?script=sci_arttext\&pid=S0103-

90162004000300010\&lng=en\&nrm=iso>. DOI: 10.1590/S0103-90162004000300010.

MANSOUR, S. R.; ABDEL-AZEEM, A. M.; ABO-DERAZ, S. S. S. A new record of Actinobacteria isolated from soil in Jerusalem and their enzymatic potential. F1000Research, v. 4, n. 11, p. 1-10, 2015. DOI: 10.12688/f1000research.3257.1.

OLIVEIRA, A. N.; FLOR, N. S.; OLIVEIRA, L. A. Influência do pH e temperatura sobre a atividade amilolítica de rizóbios isolados de solos da Amazônia. Acta Amazonica, Manaus, v. 40, p. 401-404, 2010. Disponível em: < http://www.scielo.br/pdf/aa/v40n2/v40n2a19>.

OLIVEIRA, A. N.; OLIVEIRA, L.A.; ANDRADE, J.S.; CHAGAS JÚNIOR, A.F. Atividade enzimática de isolados de rizóbios nativos da Amazônia central crescendo em diferentes níveis de acidez. Ciência, tecnologia e alimentos, v. 26, n.1, p. 204210, 2006. Disponível em: <http://dx.doi.org/10.1590/S0101-20612006000100032>. DOI: 10.1590/S0101-20612006000100032.

OSHONE, R.; MANSOUR, S. R.; TISA, L. S. Effect of salt stress on the physiology of Frankia sp strain Ccl6. Journal of Biosciences, v. 38, n. 4, p. 699-702, 2013. Disponível em: <https://link.springer.com/article/10.1007/s12038-013-9371-2>. DOI: 10.1007/s12038-013-9371-2.

PALANIYANDI, S. A.; DAMODHARAN, K.; YANG, S. H.; SUH, J. W. Streptomyces sp. strain PGPA39 alleviates salt stress and promotes growth of 'Micro Tom' tomato plants. Journal of Applied Microbiology, v.117, n.3, p.766-773, 2014. Disponível:<https://onlinelibrary.wiley.com/doi/full/10.1111/jam.12563>. DOI: 10.1111/jam.12563.

PANDE, S.; MERKER, H.; BOHL, K.; REICHELT, M.; SCHUSTER, S. et al. Fitness and stability of obligate cross-feeding interactions that emerge upon gene loss in bacteria. The International Society for Microbial Ecology Journal, 8: 953- 962, 2014. Disponível:<https://www.nature.com/articles/ismej2013211>. DOI: 10.1038/ismej.2013.211.

PINHEIRO, M. S.; SOUSA, J. B.; BERTINI, C. H. C. M.; MARTINS, S. C. S.; MARTINS, C. M. Isolamento e seleção de estirpes de rizóbios nativas do semiárido 
tolerantes a estresses ambientais. Enciclopédia Biosfera, v. 10, n. 18, p. 20712082, 2014.

R DEVELOPMENT CORE TEAM (2011) R: A language and environment for statistical computing. $R$ Foundation for Statistical Computing, Vienna. http://www.R-project.org.

RAMOS, K. A.; BRITO, F. A. E.; NUNES, K. J. F.; MARTINS, C. M.; MARTINS, S. C. S. Characterization and crhomogenic diversity of actinobacteria from undisturbed microbial niche in the caatinga biome. Enciclopédia Biosfera, v. 11, p. 2115-2125, 2015.

SANOMIYA, L. T.; NAHAS, E. Hydrolases producers microorganisms involved in the soil carbon and nitrogen cycling. Ciência Rural, v. 33, n. 5, p. 835-842, 2003. Disponível:<http://www.scielo.br/scielo.php?script=sci_arttext\&pid=S0103-

$84782003000500007 \&$ Ing=en\&nrm=iso>. DOI: 10.1590/S0103-84782003000500007.

SHIVLATA, L.; SATYANARAYANA, T. Thermophilic and alkaliphilic Actinobacteria: biology and potential applications. Frontiers in Microbiology, v. 6, p. 1-29, 2015. Disponível em: <https://www.frontiersin.org/articles/10.3389/fmicb.2015.01014/full>. DOI: $10.3389 /$ fmicb.2015.01014.

SILVA, V. M. A. Facilitação pode incrementar a capacidade de adaptação de actinobactérias e rizóbios "in vitro". 2016. Dissertação (Mestrado em Ecologia de Recursos Naturais) - Universidade Federal do Ceará, Fortaleza, 2016.

SILVA, V. M. A.; LIMA, J. V. L.; GONDIM, P. M.; MARTINS, C. M.; MARTINS, S. C. $S$. Effect of irrigation and type of cultivation on richness and diversity of chromogenic actinobacteria of soil from Ceará semiarid region. Enciclopédia Biosfera, v. 11, p. 2965-2979, 2015.

SOUSA, C. S.; SOARES, A. C. F.; GARRIDO, M. S. Characterization of streptomycetes with potential to promote plant growth and biocontrol. Scientia Agricola, v. 65 , n. 1 , p. 50-55, 2008. Disponível:<http://www.scielo.br/scielo.php? pid=S0103-90162008000100007\&script=sci_arttext $>$ DOI: 10.1590/S010390162008000100007

SOUZA, L. H.; FERREIRA NOVAIS, R.; ALVAREZ V, V. H.; ALBUQUERQUE VILLANI, E. M. D. Efeito do pH do solo rizosférico e não rizosférico de plantas de soja inoculadas com Bradyrhizobium japonicum na absorção de boro, cobre, ferro, manganês e zinco. Revista Brasileira de Ciência do Solo, v. 34, n. 5, p. 16411652, 2010. Disponível:<http://www.redalyc.org/html/1802/180215650017/>.

SUDHARHSAN, S.; SENTHILKUMAR, S.; RANJITH, K. Physical and nutritional factors affecting the production of amylase from species of Bacillus isolated from spoiled food waste. African Journal of Biotechnology, v. 6, n. 4, p. 430-435, 2007. Disponível em: <https://www.ajol.info/index.php/ajb/article/view/56233>.

SUNEETHA, V.; RAJ, K; PRATHUSA, K. Isolation and identification of Streptomyces ST1 and ST2 strains from tsunami affected soils: morphological and biochemical 
studies. Journal of Oceanography and Marine Science, v. 2, p. 96-101, 2011. Disponível:<http://www.academicjournals.org/journal/JOMS/articleabstract/CBEE7FF1716>

VAN DER MAAREL, M. J.; VAN DER VEEN, B.; UITDEHAAG, J. C.; LEEMHUIS, H.; DIJKHUIZEN, L. Properties and applications of starch-converting enzymes of the $\alpha-$ amylase family. Journal of Biotechnology, v. 94, n. 2, p. 137-155, 2002. Disponível:<https://www.sciencedirect.com/science/article/pii/S0168165601004072> DOI: 10.1016/S0168-1656(01)00407-2.

ZANELLA, M. E. Considerations on climate and water resources of the Northeastern semiarid. Caderno Prudentino de Geografia, n. 36, p. 126-142, 2014. Disponível em: <http://revista.fct.unesp.br/index.php/cpg/article/view/3176>

ZENOVA, G. M.; MANUCHAROVA, N. A.; ZVYAGINTSEV, D. G. Extremophilic and extremotolerant actinomyces in diferent soil typis. Eurasian Soil Science, v. 44, p. 417-436, 2011. Disponível:<https://link.springer.com/article/10.1134/S1064229311040132\#citeas>. DOI: $10.1134 / S 1064229311040132$. 